\title{
Electrochemical Biosensing of Salicylate by Recombinant Escherichia coli Cells Immobilized in Polyvinyl Alcohol Beads
}

\author{
Da Young Lee, In Young Jeong, Deog Su Park ${ }^{1}$ and Hae Ja Shin* \\ Division of Energy and Bio-engineering, Dongseo University, \\ Busan, 617-716, Republic of Korea \\ 'Institute of BioPhysio Sensor Technology, Pusan National University, \\ Busan, 609-735, Republic of Korea
}

(Received October 4, 2013; accepted January 24, 2014)

Key words: electrochemical microbial biosensor, salicylate, recombinant Escherichia coli

Electrochemical measurement of salicylate was performed using recombinant Escherichia coli cells immobilized in polyvinyl alcohol (PVA) beads. Among aromatic hydrocarbons, salicylate is chosen as a model compound because it is less toxic than other aromatic hydrocarbons and soluble in water. Recombinant $E$. coli cells carrying $n a h R$ (encoding the NahR regulatory protein for naphthalene and salicylate degradation)::lacZ fusion genes were constructed, immobilized in PVA beads and induced with salicylate, and their biosensing activities were electrochemically monitored using $p$-aminophenyl- $\beta$-D-galactopyranoside (PAPG) as the enzymatic substrate. The redox response of $p$-aminophenol (PAP), a catabolite of PAPG, was measured by either cyclic voltammetry (as the peak current) or chronoamperometry (as the steady-state current). Various parameters were characterized, including optimum reaction conditions, substrate concentrations, selectivity, repeatability, and stability. Under optimum conditions, the sensor showed a good lower detection limit ( $30 \mathrm{nM}$ salicylate) and selective response to salicylate. The responses were reliably repeatable with an acceptable standard deviation $( \pm 4.5 \% ; n=5)$, and the system showed good stability, with $80-100 \%$ activity remaining after $7 \mathrm{~h}$ of operation or 2 weeks of storage at $4{ }^{\circ} \mathrm{C}$. This system has advantages over existing optical techniques, including better speed and a lower detection limit.

\section{Introduction}

Aromatic hydrocarbons, many of which are listed as US Environmental Protection Agency priority chemicals, ${ }^{(1)}$ have been widely used in chemical processes as precursors, solvents, wetting agents, surfactants, insecticides, dyes, and antifoulants. Many efforts "Corresponding author: e-mail: hjshin@gdsu.dongseo.ac.kr 
have been made to monitor toxic aromatic hydrocarbons using various analytical instruments, including microbial biosensors, ${ }^{(2-8)}$ which have been extensively studied for their potential use in rapid, sensitive, and cost-effective analytical devices. ${ }^{(9-12)}$ In recent years, numerous recombinant microbial biosensors have been constructed by fusing a reporter gene (i.e., $l u c, l a c Z$ or $g f p$ ) with regulatory genes that are responsive to the target chemicals or signals. ${ }^{(12)}$ Several transducers have been used in the construction and monitoring of microbial biosensors. Electrochemical transducers convert biological signals into electrochemical signals such as currents, potentials and conductivities. Amperometric microbial biosensors have been widely developed to monitor biochemical oxygen demand (BOD), ${ }^{(13,14)}$ organophosphate, ${ }^{(15)}$ and heavy metals. ${ }^{(16)}$ Potentiometric microbial biosensors have been used to measure organophosphate with $\mathrm{pH}$ electrodes, ${ }^{(17)}$ sucrose and BOD with oxygen electrodes, ${ }^{(18,19)}$ and urea with $\mathrm{NH}_{4}{ }^{+}$ion-selective electrodes. ${ }^{20)}$ Some amperometric microbial biosensors require an electroactive mediator, such as anthraquinone ${ }^{(21)}$ or ferricyanide, ${ }^{(22)}$ to improve their electrochemical responses. Notably, electrochemical microbial biosensors typically show good sensitivity and stability, but relatively poor selectivity. ${ }^{(23)}$

In our previous work, we extensively studied microbial biosensors that use optical transducers based on bioluminescence or color development to sense benzene, toluene, ethylbenzene, and xylene (BTEX), ${ }^{(4)}$ phenolic compounds, ${ }^{(2,8,24)}$ and salicylate. ${ }^{(5,7,25)}$ We found that luciferase- or $\beta$-galactosidase-based microbial biosensors could quantitatively detect aromatic compounds in the relatively high concentration ranges of $0.01-1 \mathrm{mM}$ or $0.01-100 \mathrm{mM}$, respectively. ${ }^{(2,4,5,7,8,24)}$ Such reactions usually required the addition of a substrate or other reagents, and the activation of enzymes and accumulation of their products typically took about $3-7 \mathrm{~h} \cdot{ }^{(4,7,24)}$ Considering that environmental contamination by aromatic hydrocarbons can exist at lower concentrations, we must develop faster, more sensitive biosensors for the on-site monitoring of these compounds.

In the present study, we examined the use of an electrochemical transducer for the rapid and sensitive determination of salicylate. Recombinant $E$. coli cells harboring the plasmid pLZNRSAL (encoding the NahR regulatory protein and $\beta$-galactosidase) were immobilized in polyvinyl alcohol (PVA) and used to electrochemically sense the presence of salicylate as a model compound of aromatic hydrocarbons. For electrochemical measurements, we added $p$-aminophenyl- $\beta$-D-galactopyranoside (PAPG, a substrate of $\beta$-galactosidase), and monitored the oxidation of $p$-aminophenol (PAP, a catabolite of PAPG) by cyclic voltammetric or chronoamperometric measurements under optimum conditions. Finally, the electrochemical biosensor was analytically characterized.

\section{Materials and Methods}

\subsection{Chemicals}

The media components were purchased from Difco (MO, USA). PAPG, PVA, and boric acid were purchased from Sigma (MO, USA). The genomic DNA isolation kit, plasmid isolation spin kit, and gel extraction kit were purchased from Q-BIO Gene (CA, USA), Qiagen (Hilden, Germany), and Cosmogenetech (Seoul, Korea), respectively. SacI, XhoI, SalI, HindIII, and T4-DNA ligase were purchased from Takara (Shiga, 
Japan). The pSV-beta-gal plasmid and pGL3b basic vector were purchased from Promega (WI, USA). All other reagents were of analytical grade and were used as received without further purification.

\subsection{Bacteria and culture conditions}

Escherichia coli DH5a (hsdR, recA, Thi-1, relA1, gyrA96) was used to maintain plasmids. Pseudomonas putida KCTC1768 was obtained from the Korean Collection for Type Cultures (KCTC) and grown in tryptic soy broth at $25^{\circ} \mathrm{C}$. E. coli BL21 (hsdS, gal, ëclts857, ind1, sam7, nin5, lacUV5-T7gene1) was used for the maintenance of plasmids and expression of the NahR protein. E. coli DH5 $\alpha$ and BL21 harboring plasmids were cultured at $37{ }^{\circ} \mathrm{C}$ in TYS media ( $1 \%$ tryptone, $0.5 \%$ yeast extract, and $0.5 \% \mathrm{NaCl}$ ) containing $30 \mu \mathrm{g} \mathrm{ml}^{-1}$ ampicillin. The number of colony forming units (CFUs) per culture sample $(\mathrm{ml})$ was determined by serially diluting the sample and plating the cells on Luria-Bertani agar.

\subsection{Construction of plasmid pLZNRSAL}

Genomic DNA was isolated from P. putida KCTC 1768 and the $n a h R$ gene was PCR amplified according to the Takara Ex Taq (Japan) manual, using primers designed to introduce $\mathrm{SacI}$ and $\mathrm{XhoI}$ sites at each end (forward 5'-CGC GAG CTC TCA ATT CTC TCT ATC CTG CGA-3', reverse 5'-CCG CTC GAG GCT GTA CTC GTG ATG GCT TTA-3'). The resultant PCR products were gel-isolated and digested with $\mathrm{SacI}$ and XhoI. To construct the reporter vector, pGLacZ $(\sim 6.6 \mathrm{~kb})$, the lac $Z$ fragment $(\sim 3.7 \mathrm{~kb})$ of pSVbeta-gal was digested with SalI and HindIII and inserted into pGL3b basic $(\sim 2.9 \mathrm{~kb})$ digested with the same enzymes, and then gel-isolated to remove the luciferase reporter gene. The $n a R / P r / P s a l$ fragment $(\sim 1.3 \mathrm{~kb})$ was introduced upstream of the lac $Z$ gene in the pGLacZ vector to generate pLZNRSAL $(\sim 7.9 \mathrm{~kb})$ (Fig. 1). Plasmids were isolated with a Qiagen spin column kit and transformed into E. coli $\mathrm{DH} 5 \alpha$ by the $\mathrm{CaCl}_{2}$ method. Cloning, ligation, and transformation were carried out using standard methods. ${ }^{(26)}$

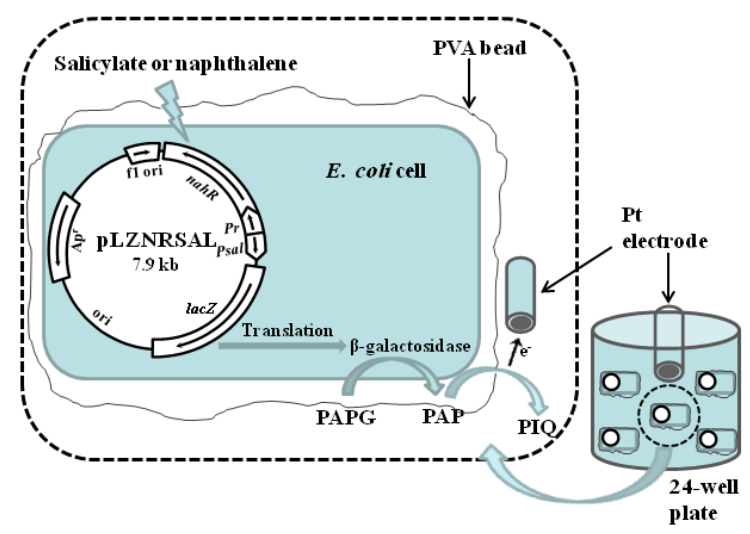

Fig. 1. (Color online) Schematics of plasmid pLZNRSAL and biosensor system. 


\subsection{Immobilization of bacterial cells}

E. coli cells harboring pLZNRSAL were grown for $16 \mathrm{~h}$ at $37{ }^{\circ} \mathrm{C}$ with shaking, and then harvested by centrifugation at $10,000 \mathrm{rpm}$ for $15 \mathrm{~min}$. The supernatant was discarded and the cells were washed with $50 \mathrm{mM}$ PBS buffer ( $\mathrm{pH} 7.4$ ). To optimize immobilization in the PVA beads, various amounts $(0.3,0.5,0.7,0.9$, or $1 \mathrm{~g})$ of PVA (nominal degree of polymerization $=1750$; approx. molecular weight $75,000-80,000$ ) were solubilized in $5 \mathrm{ml}$ of distilled hot water, dissolved completely in a boiling water bath, and then cooled to $40{ }^{\circ} \mathrm{C}$. An equal volume of cells (approximately $2.1 \times 10^{9}$ CFU) was mixed with the dissolved PVA solution, and this mixture was dropped into a saturated boric acid solution for bead formation. The resulting beads were soaked in 0.5 $\mathrm{M}$ sodium orthophosphate for $1 \mathrm{~h}$, washed with saline, and then either directly assayed electrochemically (see below) for $\beta$-galactosidase activity or stored at $4{ }^{\circ} \mathrm{C}$ until use.

\subsection{Apparatus and electrochemical measurement of $\beta$-galactosidase activity}

Cyclic voltammetry and chronoamperometry were performed using a potentiostat/ galvanostat (Cosentech, Korea). All operations, including data acquisition, were completely controlled using PC software (Cosentech, Korea). The three-electrode system consisted of a platinum $(\mathrm{Pt})$ working electrode, a $\mathrm{Ag} / \mathrm{AgCl}$ reference electrode, and a $\mathrm{Pt}$ auxiliary electrode. The working electrode was $3 \mathrm{~mm}$ in diameter and had a working area of $0.071 \mathrm{~cm}^{2}$. Microbial cells were immobilized and loaded into the electrochemical workstation, and $\beta$-galactosidase activity was electrochemically measured using PAPG as the substrate. $\beta$-galactosidase expressed in the presence of salicylate hydrolyzes PAPG to PAP, which is further oxidized to $p$-iminoquinone (PIQ) at the Pt working electrode, generating a current. The three electrodes were placed in contact with the PVA-immobilized bacterial cells in the wells of a 24-well plate containing appropriate volumes of test solution. When the background signal stabilized, PAPG was added to the reaction wells, generating an instant current response. For amperometric measurement of PAP, the potential of the Pt electrode was maintained at $300 \mathrm{mV}$ versus the $\mathrm{Ag}$ / $\mathrm{AgCl}$ electrode. For cyclic voltammetry measurements, bacterial cells with or without salicylate induction were placed in PBS buffer containing $15 \mathrm{mM}$ PAPG, and after 15 min, cyclic voltammograms were recorded (cyclic scan range, -100 to $+500 \mathrm{mV}$; scan rate, $100 \mathrm{mV} \mathrm{s}^{-1}$ ). All experiments were carried out at room temperature. Optimum experimental conditions were assessed in terms of $\mathrm{pH}(\mathrm{pH} \mathrm{6-8),} \mathrm{amount} \mathrm{of} \mathrm{cell} \mathrm{loading}$ $\left(0.7 \times 10^{9}-4.2 \times 10^{9} \mathrm{CFU}\right)$, induction time $(1-3 \mathrm{~h})$, and salicylate concentration [10 $\mathrm{nM}-1 \mathrm{mM}$ ]. For assessment of selectivity, biosensor activity was assessed in response to $0.5 \mathrm{mM}$ salicylate, phenol, BTEX, sucrose, histidine or cysteine spiked into $50 \mathrm{mM}$ PBS buffer ( $\mathrm{pH}$ 7.4) or untreated wastewater. Response repeatability was determined on the basis of the standard deviation from five consecutive measurements, while response stability was monitored over $7 \mathrm{~h}$ or after 2 weeks of storage at $4{ }^{\circ} \mathrm{C}$.

\section{Results and Discussion}

\subsection{Biosensor plasmid and system construction}

Some microorganisms, especially Pseudomonas species, can degrade naphthalene as a carbon and energy source when naphthalene and salicylate are available. ${ }^{(5,27,28)}$ 
Induction requires the product of only one regulatory gene, $n a h R$, and the presence of salicylate. ${ }^{(27,28)}$ The NahR regulatory protein activates transcription of the nah and sal operons through the interaction with the promoters Pnah and Psal for naphthalene degradation in response to the inducer salicylate..$^{(7,27,28)}$ This could be exploited as a biosensing element for a microbial biosensor system. The $n a h R$ gene, its own expression promoter $P r$, and the promoter Psal were PCR amplified from P. putida KCTC 1768, and the resulting PCR product ( 1.3 kb $n a R / P r / P s a l$ fragment) was introduced upstream of the lac $Z$ gene in the pGLacZ expression vector to generate pLZNRSAL ( 7.9 kb) (Fig. 1). E. coli DH5 $\alpha$ cells were transformed with pLZNRSAL and immobilized in PVA beads, and the sensing abilities of these beads were assessed by electrochemical measurement of $\beta$-galactosidase activity, using PAPG as the substrate. $\beta$-galactosidase, which is expressed in the presence of salicylate, hydrolyzes PAPG to PAP, which is further oxidized to PIQ at the Pt working electrode, generating a current (Fig. 1).

\subsection{Immobilization}

It was previously reported that the tolerance, operational stability, and long-term use of biosensor cells can be increased by their immobilization on support matrices or transducers. ${ }^{(29,30)}$ Among several methods, PVA was chosen because it is cheap, water soluble, nontoxic to microorganisms, and has a large porous surface that minimizes mass transfer resistance, compared with other matrices such as membranes. ${ }^{(19)}$ Various amounts of PVA were assessed in an effort to optimize cellular entrapment and the mass transfer of analyte molecules, and we found that $0.7 \mathrm{~g}$ of PVA dissolved in $5 \mathrm{ml}$ of distilled water yielded high-quality beads in terms of firmness and mass transfer (data not shown). For experiments, equal volumes of pLZNRSAL-containing $E$. coli cells $\left(\sim 2.1 \times 10^{9} \mathrm{CFU}\right)$ and PVA were mixed to make cell-immobilized PVA beads (Fig. 2), and the biosensing abilities of the cell-loaded beads were then assessed by electrochemical monitoring of $\beta$-galactosidase activity. Viabilities were also indirectly determined as $\beta$-galactosidase activities compared before and after entrapment, showing that $\beta$-galactosidase activities after entrapment were almost the same as those before entrapment (data not shown). PVA created a three-dimensional structure that could reduce the transfer resistance of electrons resulting in increased currents, as mentioned in a previous report. ${ }^{(19)}$ Therefore, we used PVA beads for the immobilization of biosensor cells in the following experiments.

\subsection{Electrochemical measurements of $\beta$-galactosidase activity}

For rapid analyses of multiple samples, cyclic voltammograms were used to examine the electrochemical responses of various reaction solutions (Fig. 3), including PBS buffer alone and PBS buffer containing $E$. coli cells with or without salicylate induction followed by incubation with $15 \mathrm{mM}$ PAPG for $15 \mathrm{~min}$ (this time was selected in our optimization experiments, see below). The PBS buffer did not interfere with the redox responses of PAP (Fig. 3). The current did, however, respond to the hydrolysis of PAPG; an increased and shifted oxidation peak appeared after hydrolysis of PAPG by $\beta$-galactosidase in salicylate-induced E. coli cells (Fig. 3). As the concentration of PAPG increased, the oxidation current peak of PAP also increased (data not shown). These results indicate that the increased and shifted current generation was due to the oxidation 


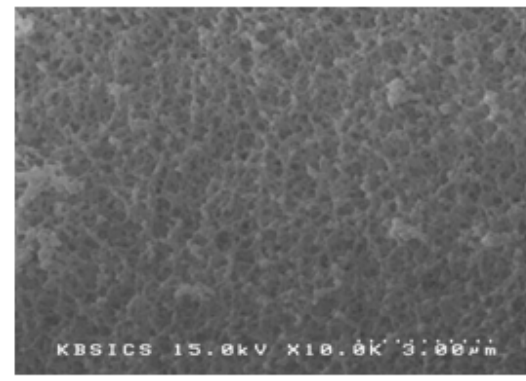

(a)

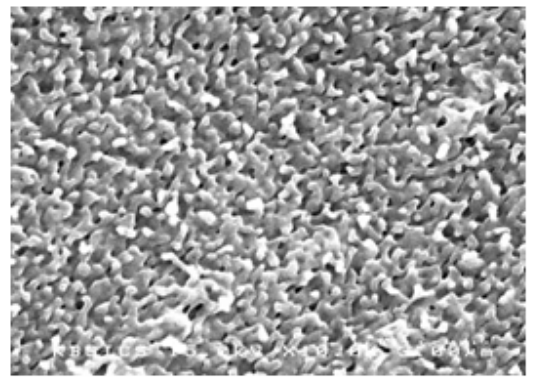

(b)

Fig. 2. SEM images of control PVA beads (a) and cell-immobilized PVA beads (b).

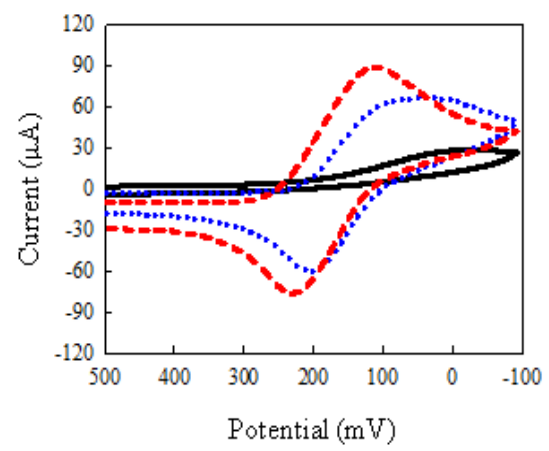

Fig. 3. (Color online) Cyclic voltammograms of $50 \mathrm{mM}$ PBS buffer (solid line), and $50 \mathrm{mM}$ PBS buffer plus $15 \mathrm{mM}$ PAPG and E. coli biosensor cells without (dotted line) or with (dashed line) salicylate induction, taken at a scan rate of $100 \mathrm{mV} \mathrm{s}^{-1}$.

of PAP. There was no difference in the cyclic voltammograms of reactions containing PAPG and PAPG plus salicylate in the absence of biosensor cells (data not shown). The mean value of the anodic and cathodic peak potentials of the cyclic voltammogram was about $+220 \mathrm{mV}$ versus the $\mathrm{Ag} / \mathrm{AgCl}$ reference electrode. This value was in close agreement with that of a previous study, ${ }^{(16,31)}$ and it has been reported that no other electroactive species except for PAP exists at around this potential. ${ }^{(31)}$ Therefore, the potential of the $\mathrm{Pt}$ working electrode was set at $300 \mathrm{mV}$ versus the $\mathrm{Ag} / \mathrm{AgCl}$ electrode for the subsequent amperometric measurements.

\subsection{Optimization}

Since microbial biosensors exploit living microorganisms as sensing elements, and living cells require certain conditions for viability and activity, we next sought to optimize our experimental conditions. We assessed the responses of pLZNRSAL- 
containing $E$. coli cells in terms of salicylate induction time, $\mathrm{pH}$, and the number of cells loaded for immobilization. To assess the salicylate induction time, E. coli cells were incubated with $0.5 \mathrm{mM}$ salicylate (this concentration showed best current responses in preliminary experiments) for 1,2 or $3 \mathrm{~h}$, and current responses were monitored [Fig. 4(a)]. The current response depended greatly on the induction time. The most marked response was observed with $2 \mathrm{~h}$ induction, when the expression of $\beta$-galactosidase apparently seemed to reach the maximum. The current response increased up to $\sim 10 \mathrm{~min}$ and then reached a stationary state [Fig. 4(a)], indicating that the $\beta$-galactosidase reaction and PAP measurement took approximately $\sim 10 \mathrm{~min}$. In total, $\sim 15 \mathrm{~min}$ was required for the preparation, reaction, and measurement steps, and we therefore performed our subsequent cyclic voltammograms $15 \mathrm{~min}$ after the addition of PAPG. This is significantly shorter than the time required for optical measurements of $\beta$-galactosidase activity based on color development, which typically take up to 5-7 h with intact cells or 1-3 h with lysed cells. ${ }^{(8)}$ The current response was decreased with $3 \mathrm{~h}$ induction, which was similar to our previous results that longer incubation with PAHs could be detrimental to cells. ${ }^{(12)}$ We then assessed the optimum cell loading amount for immobilization, and observed the best response with $\sim 2.1 \times 10^{9} \mathrm{CFU}$ [Fig. 4(b)]. Higher cell amounts decreased the current responses, which was consistent with a previous report suggesting that too many cells may hamper electron transfer to the Pt working electrode, decreasing the oxidation current. ${ }^{(19)}$ Finally, the optimum $\mathrm{pH}$ for the system was tested and found to be around $\mathrm{pH}$ 6-7.5, which is known to be the optimum $\mathrm{pH}$ for E. coli. We used PBS buffer ( $\mathrm{pH}$ 7.4) since it is a common physiological buffer and does not interfere with current responses. All subsequent experiments were done under optimum conditions.

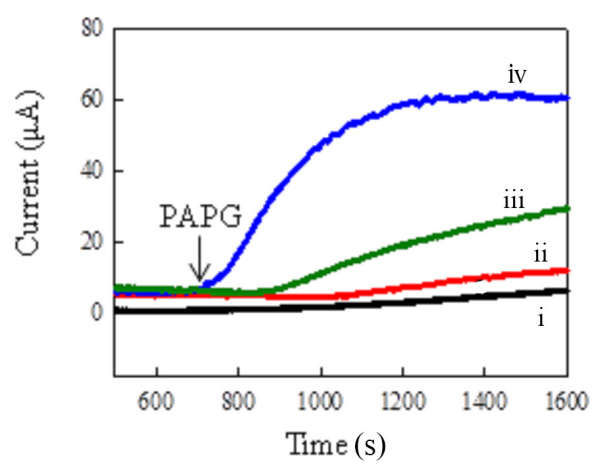

(a)

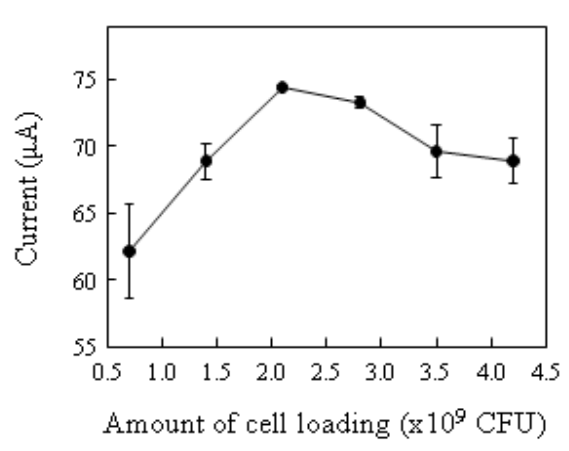

(b)

Fig. 4. (Color online) Optimum induction time in the presence of salicylate (a) and optimum cell loading amount for immobilization (b). The optimum induction time (i, control; ii, $3 \mathrm{~h}$ induction; iii, $1 \mathrm{~h}$; iv, $2 \mathrm{~h}$ ) was determined by amperometric measurements at $+300 \mathrm{mV}$ vs the $\mathrm{Ag} / \mathrm{AgCl}$ reference electrode, while optimum cell loading was assessed by cyclic voltammetry at a scan rate of $100 \mathrm{mV} \mathrm{s}^{-1}$. 


\subsection{Sensitivity}

Sensitivity is vital to the performance of microbial biosensors. We began by hypothesizing that electrochemical measurement of $\beta$-galactosidase might be more sensitive and rapid than the conventional optical measurements, since PAP is oxidized at the Pt electrode and can be directly converted to a current signal without needing time to accumulate. Different concentrations of salicylate (10 $\mathrm{nM}$ to $1 \mathrm{mM})$ were tested and $\beta$-galactosidase activities were monitored by cyclic voltammetry. Current responses were present in experiments containing $10 \mathrm{nM}$ salicylate, peaked at $0.5 \mathrm{mM}$, and decreased thereafter (Fig. 5). We further assessed $1 \mathrm{nM}, 5 \mathrm{nM}, 5 \mathrm{mM}$, and $10 \mathrm{mM}$ salicylate; we obtained no detectable responses with 1 and $5 \mathrm{nM}$, and the responses to 5 and $10 \mathrm{mM}$ were lower than those to $1 \mathrm{mM}$ (data not shown). Thus, the lower detection limit ( $3 \mathrm{~S} / \mathrm{m} ; 3$ times standard deviation/slope of regression curve) appeared to be 30 $\mathrm{nM}$. Therefore, our electrochemical measurement of salicylate was more sensitive than the previously reported optical measurements using luciferase reporter systems, which had sensitivities in the $\mu \mathrm{M}-\mathrm{mM}$ range for salicylate. ${ }^{(5,7)}$ The luciferase reporter system is generally much more sensitive than the $\beta$-galactosidase system, making this result rather remarkable. The increased sensitivity of our system may be attributed to the use of an electrochemical sensing system, which had a maximum response at $0.5 \mathrm{mM}$ compared with the $1 \mathrm{mM}$ maximum of some optical measurements. However, the upper detection limit of our system was $\sim 1 \mathrm{mM}$, compared with $\sim 10 \mathrm{mM}$ with the previously reported optical system. ${ }^{(5)}$ This suggests that electrochemical measurement is more sensitive at lower concentrations of salicylate, while optical measurement performs better at higher concentrations. Overall, the calibration plot for electrochemical measurement of our biosensor cells showed good linearity with regard to salicylate concentrations from 0.001 to $0.05 \mathrm{mM}$ (regression curve; $y=4.67 \log x+5.89 ; R^{2}=0.97$ ).

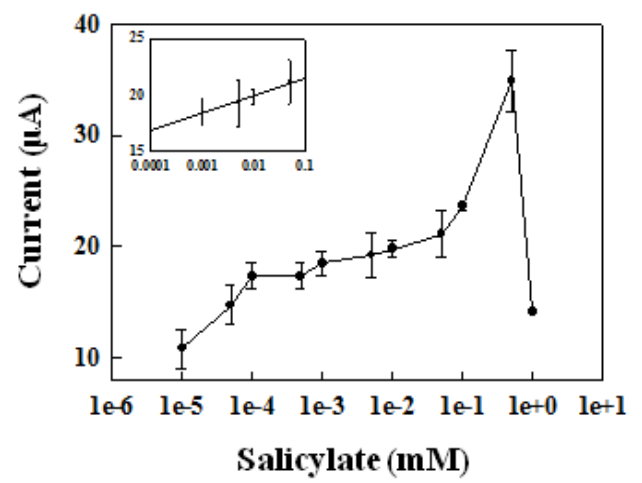

Fig. 5. Electrochemical measurements of $\beta$-galactosidase activities in response to various salicylate concentrations. Immobilized cells were treated with $10 \mathrm{nM}$ to $1 \mathrm{mM}$ salicylate for $2 \mathrm{~h}$, and cyclic voltammetry was used to assess $\beta$-galactosidase activity at a scan rate of $100 \mathrm{mV} \mathrm{s}^{-1}$. The cathodic peak current was corrected for the peak current measured in the absence of salicylate. The regression curve $\left(y=4.67 \log x+5.89 ; R^{2}=0.97\right)$ is shown in the inset (linearity between 0.001 and $0.05 \mathrm{mM})$. 


\subsection{Specificity, repeatability, and stability}

The selectivity of the system was electrochemically monitored using pLZNRSALcontaining E. coli cells induced with $0.5 \mathrm{mM}$ salicylate, phenol, BTEX, sucrose, histidine, or cysteine spiked into buffer or untreated wastewater (Table 1). The response current was corrected for the current measured in control (a basal $\beta$-galactosidase activity of cells in the absence of inducer under the same conditions). The result clearly indicates that the system can be used for the preliminary detection of aromatic compounds in contaminated wastewater. However, the current levels measured in wastewater were slightly lower than the values in the buffer, suggesting that some impure chemicals in wastewater might affect the result. Specific responses were obtained for salicylate, indicating that the NahR regulatory protein was different from the BTEX-induced XylR regulatory protein ${ }^{(2)}$ or the phenol-induced CapR regulatory protein. ${ }^{(5)}$ However, weaker responses were obtained for benzene and ethylbenzene. We previously observed in a luciferase reporter system that mutant biosensor cells responded to induction by both salicylate and benzoate, whereas wild-type NahR responds only to salicylate. ${ }^{(5,7)} \mathrm{We}$ speculated that the structural similarity of benzoate to salicylate might allow partial binding of benzoate to the mutant NahR protein. The present system utilized the wildtype NahR protein, however, assuming that the electrochemical system has relatively poor selectivity, as reported previously. ${ }^{(23)}$ Further research on the structural and functional interactions of NahR with its inducer(s) might be required to fully explain these observations.

Repeatability and stability are widely used to assess matrix-immobilized biosensors. Repeatability is defined as the standard deviation of a single sensor tested under the same conditions. ${ }^{(19)}$ The repeatability of our system was tested by five consecutive assessments of the system in response to $0.5 \mathrm{mM}$ salicylate, and was found to be relatively good (standard deviation, $\pm 4.5 \%, n=5$ ). The operational stabilities were monitored by measuring electrochemical current responses over $7 \mathrm{~h}$ (Fig. 6), while storage stabilities

Table 1

Electrochemical biosensor selectivity.

\begin{tabular}{lccc}
\hline \multirow{2}{*}{ Compounds $^{\mathrm{a}}$} & \multirow{2}{*}{ Concentration $(\mathrm{mM})^{2}$} & \multicolumn{2}{c}{ Current $(\mu \mathrm{A})^{\mathrm{b}}$} \\
\cline { 3 - 4 } Salicylate & 0.5 & $61 \pm 4.2$ & $52.7 \pm 7.7$ \\
Phenol & 0.5 & 0 & 0 \\
Benzene & 0.5 & $18 \pm 4.7$ & $16 \pm 6.2$ \\
Ethyl benzene & 0.5 & $13 \pm 5.5$ & $13 \pm 2.8$ \\
Toluene & 0.5 & 0 & 0 \\
Xylene & 0.5 & 0 & 0 \\
Sucrose & 0.5 & 0 & 0 \\
Histidine & 0.5 & 0 & 0 \\
Cysteine & 0.5 & 0 & 0 \\
\hline
\end{tabular}

aEach compound was spiked into $50 \mathrm{mM}$ PBS buffer ( $\mathrm{pH}$ 7.4) or untreated wastewater obtained from Dongseo University in South Korea. All aromatic compounds (except for salicylate) were dissolved in ethanol.

${ }^{\mathrm{b}}$ The peak current was corrected for the peak current measured in the absence of an inducer and all analyses were reported as average \pm relative standard deviation. 


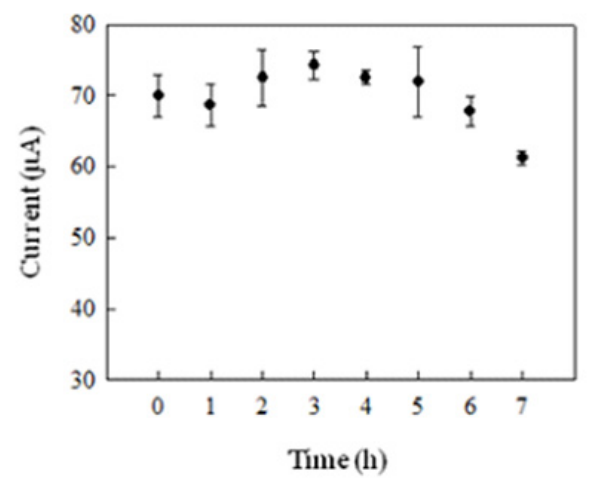

Fig. 6. Operational stability of the immobilized biosensor cells. Immobilized cells were treated with $0.5 \mathrm{mM}$ salicylate for $2 \mathrm{~h}$, and $\beta$-galactosidase activity was assessed over a period of $7 \mathrm{~h}$ by cyclic voltammetry at a scan rate of $100 \mathrm{mV} \mathrm{s}^{-1}$.

were monitored after 2 weeks of storage at $4{ }^{\circ} \mathrm{C}$ (data not shown). The activity after $7 \mathrm{~h}$ was about $90 \%$ of the initial activity, and that after 2 weeks at $4{ }^{\circ} \mathrm{C}$ was $80-100 \%$, indicating that the biosensor system has good operational and storage stability. In fact, PVA-immobilized microbial cells can reportedly be stored for up to $100 \mathrm{~d}$ without a large activity loss. ${ }^{(19)}$

\section{Conclusions}

Electrochemical measurement of salicylate was carried out using recombinant $E$. coli harboring nahR::lacZ fusion genes. The recombinant cells were immobilized in polyvinyl alcohol beads and induced with salicylate, and $\beta$-galactosidase activity was measured with PAPG as the substrate. PAP redox responses were detected as the peak current in cyclic voltammograms (scan rate of $100 \mathrm{mV} \mathrm{s}^{-1}$ ) or as the steadystate current in chronoamperograms $(+300 \mathrm{mV}$ vs the $\mathrm{Ag} / \mathrm{AgCl}$ reference). Compared with conventional optical measurements of $\beta$-galactosidase activities, the system was faster $(<15 \mathrm{~min}$ including the substrate reaction and measurement) and showed a lower detection limit $(30 \mathrm{nM})$. The repeatability of responses was within acceptable bias limits $( \pm 4.5 \%, n=5)$, and the stability tests showed that $80-100 \%$ activity remained after $7 \mathrm{~h}$ of operation or 2 weeks of storage at $4{ }^{\circ} \mathrm{C}$. Thus, our system could be developed as a rapid and highly sensitive microbial biosensor system for diverse biotechnological uses.

\section{Acknowledgements}

This work was supported by the Basic Science Research Program of the National Research Foundation of Korea (NRF) funded by the Ministry of Education, Science and Technology (2011-0007702) and partly by a grant (2012) from the Innovation Center for Engineering Education of Dongseo University and partly by a grant (2013) from Dongseo University, Republic of Korea. 


\section{References}

1 EPA, http://www.epa.gov/ostwater/methods/pollutants.htm. (Accessed in March 2011).

2 S. M. Park, H. H. Park, W. K. Lim and H. J. Shin: J. Biotechnol. 103 (2003) 227.

3 Z. Xu, A. Mulchandani and W. Chen: Biotechnol. Progr. 19 (2003) 1812.

4 H. H. Park, H. Y. Lee, W. K. Lim and H. J. Shin: Arch. Biochem. Biophys. 434 (2005) 67.

5 M. N. Kim, H. H. Park, W. K. Lim and H. J. Shin: J. Microbiol. Methods. 49 (2005) 103.

6 G. I. Paton, B. J. Reid and K. T. Semple: Environ. Pollut. 157 (2009) 1643.

7 H. J. Shin: J. Biotechnol. 150 (2010) 246.

8 S. Belkin: Curr. Opin. Microbiol. 6 (2003) 206.

9 J. R. van der Meer, D. Tropel and M. Jaspers: Environ. Microbiol. 6 (2004) 1005.

10 H. Harms, M. C. Wells and J. R. van der Meer: Appl. Microbiol. Biotechnol. 70 (2006) 273.

11 H. J. Shin: Appl. Microbiol. Biotechnol. 89 (2011) 867.

12 H. J. Shin: Appl. Microbiol. Biotechnol. 93 (2012) 1895.

13 S. Heim, I. Schnieder, D. Binz, A. Vogel and U. Bilitewski: Biosens. Bioelectron. 14 (1999) 187.

14 J. Jia, M. Tang, X. Chen, L. Qi and S. Dong: Biosens. Bioelectron. 18 (2003) 1023.

15 P. Mulchandani, W. Chen, A. Mulchandani, J. Wang and L. Chen: Biosens. Bioelectron. 16 (2001) 433.

16 I. Biran, R. Babai, K. Levcov, J. Rishpon and E. Z. Ron: Environ. Microbiol. 2 (2000) 285.

17 A. Mulchandani, P. Mulchandani, I. Kaneva and W. Chen: Anal. Chem. 70 (1998) 4140.

18 L. Rotariu, C. Bala and V. Magaru: Anal. Chim. Acta 513 (2004) 119.

19 J. Wang, Y. Zhang, Y. Wang, R. Xu, Z. Sun and Z. Jie: Biosens. Bioelectron. 25 (2010) 1705.

20 N. Verma and M. Singh: Biosens. Bioelectron. 18 (2003) 1219.

21 F. Aulenta, T. Ferri, D. Nicastro, M. Majone and M. P. Papini: New Biotechnol. 29 (2011) 126.

22 T. Mann and S. R. Mikkelsen: Anal. Chem. 80 (2008) 843.

23 Y. Lei, W. Chen and A. Mulchandani: Anal. Chim. Acta 568 (2006) 200.

24 H. J. Shin, H. H. Park and W. K. Lim: J. Biotechnol. 119 (2005) 36.

25 H. H. Park, W. K. Lim and H. J. Shin: Biochim. Biophys. Acta 1725 (2005) 247.

26 J. Sambrook, E. F. Fritsch and T. Manniatis: Molecular Cloning: A Laboratory Manual, 3rd ed. (Cold Spring Harbor Laboratory, New York, 2001).

27 J. R. van der Meer, W. M. de Vos, S. Harayama and A. J. B. Zehnder: Microbiol. Rev. 56 (1992) 677.

28 P. A. Williams and J. R. Sayers: Biodegradation 5 (1994) 195.

29 G. S. Alvarez, M. L. Foglia, G. J. Copello, M. F. Desimone and L. E. Diaz: Appl. Microbiol. Biotechnol. 82 (2009) 639.

30 S. K. Jha, M. Kanungo, A. Nath and S. F. D'Souza: Biosens. Bioelectron. 24 (2009) 2637.

31 N. Matsui, T. Kaya, K. Nagamine, T. Yasukawa, H. Shiku and T. Matsue: Biosens. Bioelectron. 21 (2006) 1202. 